Article

\title{
Ang Pilosopiya ni Jean-Francois Lyotard bilang Batayang Teoretikal sa Araling Pilipino
}

\section{F.P.A. Demeterio III}

\begin{abstract}
The aim of this paper is to expose the important aspects of Lyotard's thought using the Filipino language. The use of the Filipino language is key in providing Filipino scholars, who are into cultural studies and Philippine studies, easier access to the ideas of Lyotard. This will also prove useful to Filipinos studying philosophy. The paper focuses on four aspects of Lyotard's thought: 1) his critique of the status of scientific knowledge in the postmodern period, 2) his appraisal of the effect of postmodern science on tertiary education, 3) his insistence on the significance of ethics and justice amidst the incredulity towards grand narratives and the emergence of small narratives, and 4) his explanation regarding the role of art in the postmodern period. Towards the end of the paper, seven points will be discussed regarding how Lyotard's ideas can contribute to local cultural studies and Philippine studies.
\end{abstract}

Keywords: Lyotard, Filipino language, Philippine studies, postmodern condition

\section{Introduksyon}

$\mathrm{H}$ angarin ng papel na ito na mailahad ang mga mahalagang aspekto at puntos ng kaisipan ng Pranses na pilosopo, kritikong pampanitikan at pangkultura, at isa sa mga pangunahing teoresista ng postmodernismo na si Jean-François Lyotard (1924-1998), hindi lamang sa wikang Filipino, kung hindi lalo na sa antas ng diskursong madaling maintindihan ng mga kapwa Pilipinong nasa larangan ng araling kultural at araling Pilipino na wala pa masyadong kasanayan sa antas ng diskursong pilosopikal, at sa mga Pilipinong mag-aaral sa pilosopiya na marahil hindi pa handang basahin ang mga primaryong teksto ni Lyotard o ang mga masalimuot na komentaryong naisulat na sa wikang Ingles.

(C) 2013 F.P.A. Demeterio III http://www.kritike.org/journal/issue 13/demeterio december2013.pdf ISSN 1908-7330 
Hangarin din ng papel na ito na matukoy ang ilang aspekto at puntos mula sa naturang banyagang diskurso na may maiaambag para sa lalong pagpapayaman sa teoretikal na korpus ng lokal na araling kultural at araling Pilipino.

Si Lyotard ay ipinanganak sa Versailles at minsan nangarap na maging isang Dominikanong prayle, alagad ng sining, o historyador, ngunit nag-aral ng pilosopiya sa Sorbonne. Matapos niyang maipasa ang eksaminasyon sa pagtuturo, nagtrabaho siya sa isang sekondaryang paaralan sa lungsod ng Constantine, sa Silangang Algeria na noon ay kolonya ng Pransiya. Doon ay nasaksihan niya ang masaklap na kapalaran ng mga taong naging biktima ng kolonisasyon. Pagbalik niya sa Pransiya, naging kasapi siya sa isang Marxista ngunit anti-Stalinistang organisasyong Sosyalismo o Barbarismo (Socialisme ou Barbarie), at kalaunan sa isa pang Marxistang organisasyong Kapangyarihan ng Manggagawa (Pouvoir Ouvrier). Marami sa mga mag-aaral na sangkot sa mga kilusan at kaguluhan ng Mayo 1968 ay mga estudyante ni Lyotard habang nagtratrabaho siya bilang lecturer sa Pamantasan ng Nanterre. Nakamtan niya ang kanyang doktorado sa literatura noong siya ay 47 na taong gulang na, batay sa isang disertasyong bumatikos sa istrakturalismo at kumiling sa Freudianismo. Naging propesor siya sa pilosopiya sa Pamantasan ng Paris VIII, at matapos siyang magretiro ay nagturo sa maraming pamantasan sa Estados Unidos ng Amerika, Kanada, Timog Amerika at Europa. Namatay siya sa sakit na leukemia sa lungsod ng Paris, sa edad na 74.

Ilan sa mga pangunahing libro na nailathala ni Lyotard ay ang Libidinal Economy ng 1974, Duchamp's Transformers ng 1977, The Postmodern Condition ng 1979, Just Gaming ng 1979, The Differend: Phrases in Dispute ng 1983, Heidegger and 'The Jews' ng 1988, The Inhuman: Reflections on Time ng 1988, Peregrinations: Law, Form, Event ng 1990, Lessons on the Analytic of the Sublime: Kant's Critique of Judgment ng 1991, Postmodern Moralities ng 1993, at Signed, Malraux: Biography ng 1996. Bukod sa pagdala sa kategoryang "postmodernismo" sa diskursong pilosopikal mula sa mundo ng sining at kultura, kilala si Lyotard dahil sa kanyang mga tagapagbunsod na pag-aaral sa postmodernong sining, pelikula, musika, panahon, espasyo, hugis ng lungsod (cityscape), at pulitika, at higit na kilala siya dahil sa kanyang tanyag na imbestigasyon sa estado ng kaalaman sa postmodernong lipunan. Tatalakayin ng papel na ito ang kaisipan ni Lyotard sa ilalim ng apat subseksiyon na tungkol: 1) sa kanyang pagpuna sa katayuan ng siyantipikong kaalaman sa postmodernong pahanon, 2) sa kanyang pagtaya sa magiging epekto ng postmodernong siyensiya sa tersiyaryong edukasyon, 3) sa kanyang paggiit sa saysay ng etika at katarungan sa gitna ng pagkasantabi ng mga dambuhalang naratibo at pag-iral ng mga munting naratibo, at 4) sa kanyang pagpaliwanag sa papel ng sining sa postmodernong panahon.

(c) 2013 F.P.A. Demeterio III

http://www.kritike.org/journal/issue 13/demeterio december2013.pdf ISSN 1908-7330

(cc) BY-NC 


\section{Pagpuna sa Katayuan ng Siyantipikong Kaalaman sa Postmodernong Panahon}

Ang pagpuna ni Lyotard sa katayuan ng siyantipikong kaalaman sa postmodernong panahon ay matatagpuan sa librong Postmodern Condition: a Report on Knowledge ng 1979. Para maintindihan natin nang husto ang naturang pagpuna mahalagang maintindihan muna natin ang ibig niyang sabihin sa katagang "postmodernong panahon," at sa pangkahalatahang transpormasyong dinanas ng kaalaman sa naturang temporal na punto ng kasaysayan. Para kay Lyotard, and "postmodernong panahon" ay tumutukoy sa kondisyong umiiral sa mga pinaka maunlad na lipunan mula noong kalagitnaan ng ika-dalawampung daantaon, kung kalian naisaayos na sa Europa ang mga bakas ng Ikalawang Pandaigdigang Digmaan. ${ }^{1}$ Sa loob ng panahong ito, dahil sa mga pagbabagong dulot ng siyensiya, teknolohiya at komersiyo, may mga mahalagang pagbabago na napansin si Lyotard sa anyo ng kaalaman.

Una dito ay ang kaalaman ay hindi na kinakalap para sa kapakanan ng kaalaman, sa halip ito ay kinakalap at ipinagpapalit na katulad ng ibang komoditi. Ang mga kaalamang hindi maaaring ituring na komoditi ay untiunting isinantabi, at ang katotohanan ay hindi na ang pinakasukatan ng kaalaman dahil napalitan na ito ng sukatan na gamit (utility) at pagkamabenta (marketability). ${ }^{2}$ Ang mga postmodernong indibiduwal ay hindi na interesado sa katanungang "totoo ba yan?" kung hindi sa mga katanungang "may gamit ba yan?" o "may bibili ba niyan?."3 Kung noon pinag-aagawan ng mga estado ang lupain, mga likas na yaman katulad ng langis at produktong agrikultural, at mga lokasyon at daanan ng komersiyo at merkado, tinataya ni Lyotard na dadating ang araw kung kailan ang pagaagawan naman ng mga estado at higanteng korporasyon ay ang pagkontrola at paggamit sa mga nakaimbak na kalaaman. ${ }^{4}$

Pangalawa dito ay ang pagkalusaw sa kapangyarihan ng mga metanaratibo, na para kay Lyotard ay mga dambuhalang kuwento na noong panahon ng modernismo ay ay nagsisilbing batayan ng lehitimasiya ng iba't ibang larangan, institusyon at diskurso ng lipunan. Isinulat niya: “binibigyan ko ng kahulugan ang postmoderno bilang kawalan ng tiwala sa mga metanaratibo." ${ }^{5}$ Itinuturing ni Lyotard ang siyensiya, relihiyon, at

\footnotetext{
1 Jean-Francois Lyotard, The Postmodern Condition: a Report on Knowledge (Minneapolis, Minnesota: University of Minnesota Press, 1984), 3.

${ }^{2}$ Ibid., 4.

${ }^{3}$ Ibid.

${ }^{4}$ Ibid., 5.

${ }^{5}$ Ibid., xxiv.
} 
maraming aspekto ng pilosopiya at ideolohiya bilang mga metanaratibo. Ang mga ideya katulad ng kasaysayan bilang kwento ng kaunlaran, siyensiya bilang may kapangyarihang alamin ang lahat, wagas na kalayaan bilang bagay na maaaring makamtan, at kaayusang walang panlipunang uri, ay mga halimbawa ng metanaratibo. ${ }^{6}$ Ang postmodernong mundo ay may inklinasyong hindi na naniniwala sa ganitong mga dambuhalang kuwento, at sa halip ay mas pumapanig sa maraming maliit na naratibong nakabatay lamang sa mga probisyonal, kontekstuwal, pansamantala at relatibong kawastuhan at pagiging tama.

Metanaratibo ang siyensiya dahil sinusunod ang mga kaalaman nito sa pagpapatakbo at pagpapalago ng ibang larangan, institusyon at diskurso, katulad ng gobiyerno at mga korporasyon. ${ }^{7}$ Sa usapin ng pagsusulong ng mga panukalang batas at proyekto, halimbawa, ginagamit ang kaalamang nauna nang nakalap ng siyensiya para mabigyan ng bigat at lehitimasiya ang mga naturang panukala. Sa burukrasya at pagpapatakbo ng mga korporasyon, isa pang halimbawa, ginagamit din ang mga kaalaman ng siyensiya para sa anumang gagawing pagdedesisyon ng mga ehekutibo. Ang siyensiya ang siyang nagbibigay ng lehitimasiya at saysay sa mga larangan, institusyon at diskursong ito at ng marami pang larangan, institusyon at diskurso. Ngunit ang siyensiya mismo, bilang isa ring larangan, institusyon at diskurso, ay nangangailangan din ng metanaratibo para mabigyang saysay at lehitimasiya ang kanyang sarili. Subalit, hindi maaaring gagamitin ng siyensiya ang gobiyerno, mga korporasyon, at kahalintulad na mga larangan, institusyon at diskurso bilang metanaratibo dahil siyensiya na nga mismo ang nagbibigay sa kanila ng saysay at lehitimasiya, at lalong hindi maaaring gagamitin ng siyensiya ang kanyang sarili bilang batayan ng kanyang pansariling saysay at lehitimasiya. Hindi rin maaaring gamitin ng siyensiya ang relihiyon at mga kahalintulad na tradisyunal na naratibo dahil ang siyensiya ay may inklinasyong isantabi ang ganitong uring naratibo bilang hindi wasto at makatotohanang diskurso at igiit na tanging siyensiya lamang ang mapagkakatiwalaang diskurso. ${ }^{8}$

Ayon kay Lyotard, noong modernong panahon, ang siyensiya ay dating humuhugot ng metanaratibo mula sa mga metapisikal na diskurso katulad ng mga ideyang ang kaalaman ng tao ay dapat magpapalaya sa kanya mula sa kahirapan, pagdurusa at karamdaman; na ang siyensiya ay kayang alamin at ayusin ang lahat ng bagay; at na ang pag-usad ng kasaysayan ay pag-usad patungo sa kaunlaran. ${ }^{9}$ Ngunit sa postmodernong

\footnotetext{
${ }^{6}$ Ibid., xxiii.

${ }^{7}$ Ibid., 28.

${ }^{8}$ Ibid., 25.

${ }^{9}$ Ibid., xxiii.
}

(C) 2013 F.P.A. Demeterio III

http://www.kritike.org/journal/issue 13/demeterio december2013.pdf

ISSN 1908-7330

(cc) BY-NC 
panahon at sa paglaganap ng kawalan ng tiwala sa mga metanaratibo at dambuhalang kuwento, pati ang dating mga nakakubling metapisikal na diskurso na ginamit ng siyensiya bilang batayan ay nalusaw at naisantabi na rin. Dahil hindi maaaring mawalan ang isang larangan, institusyon o diskurso ng batayan ng kanyang saysay at lehitimasiya, ang mga nakakubling metapisikal na diskurso sa pundasyon ng siyensiya ay napalitan ng mga elementong hinugot nito mula sa modernong rasyunalidad at kapitalismo, na walang iba kung hindi ang mga pamantayang episiyensiya (efficiency) para sa metodolohiya at pagiging kapakipakinabang at mabenta ng mga resulta. ${ }^{10}$

Malalim at malawak ang naging epekto sa anyo ng siyensiya ng pagkalusaw ng kanyang dating mga metapisikal na metanaratibo at ng pagpasok ng mga pamantayang episiyensiya at pagiging kapakipakinabang at mabenta. Ang pamantayang episiyensiya para sa metodolohiya ay nagtulak sa siyensiyang bigyan diin ang kanyang teknolohikal na kagamitan para sa pananaliksik, mga teknolohikal na gamitang madalas napakalaki ang halaga. Dahil dito ang siyensiya ay naging isang diskursong kontrolado na ng mga mayamang bansa at institusyon dahil sila lamang ay may kakayahang maglaan malaking pondo para sa episiyenteng kagamitang pananaliksik. ${ }^{11}$ Samantalang ang pamantayang pagiging kapakipakinabang at mabenta ng resulta ng pananliksik ay nagtulak sa siyensiya palapit nang palapit sa kapitalismo. Dahil kadalasan mas malaki ang suma total na pondo ng mga multinasyunal na korporasyon para sa pananaliksik kaysa pondo ng pananaliksik ng karaniwang estado nalalagpasan ng mga korporasyong ito ang katayuan ng mga karaniwang estado, at madalas dinidiktahan na lamang ng mga korporasyong ito ang mga estado. ${ }^{12}$

Kaya sa gitna ng pagkalusaw ng mga metanaratibo at sa pagusbong ng mga maliit na naratibo ay naging kontralado naman ang siyensiya ng mga mayamang bansa at higanteng korporasyon. Naniniwala si Lyotard na ang lumalagong kapangyarihan ng siyensiya na nakikipagsabwatan sa mayayamang bansa at higanteng korporasyon ay dapat harapin ng mga postmodernong indibiduwal sa pamamagitan ng lalong pagpapalakas, pagpapadami at pagkikilala sa lehitimasiya ng mga maliit na naratibo. ${ }^{13}$ Hinugot ni Lyotard ang ideyang ito mula mismo sa loob ng siyensiya kung saan napansin niya na paminsan-minsan may mga maliit at bagong kaalaman na kayang guluhin ang sistematikong diskurso ng siyensiya. Ang mga maliit at bagong kaalamang ito ay kahalintulad sa

\footnotetext{
${ }^{10}$ Ibid., 41-47.

${ }^{11}$ Ibid., 45.

12 Ibid., 5.

${ }^{13}$ Ibid., 60-67.
} 
radikal na kaalamang ayon sa Amerikanong pilosopo na si Thomas Kuhn (1922-1992) ay may kahayahang magtulak sa isang larangan ng siyensiya sa rebolusyunaryong pagpapalit ng paradigma. Umaasa si Lyotard na sa labas ng siyensiya may mga maliit na naratibo ding may kakayahang guluhin at gambalahin ang sabwatan ng siyensiya, estado at kapitalismo.

\section{Ang Implikasyon ng Postmodernong Siyensiya sa Tersiyaryong Edukasyon}

Ang diskusyon ni Lyotard sa implikasyon ng postmodernong siyensiya sa tersiyaryong edukasyon ay matatagpuan pa rin sa librong Postmodern Condition: a Report on Knowledge. Ayon sa kanya ang pagkalusaw ng metapisikal na metanaratibo ng siyensiya at ang pagpasok ng mga pamantayang episiyensiya para sa metodolohiya at pagiging kapakipakinabang at mabenta ng mga resulta nito, at ang pakikipagsabwatan ng siyensiya sa estado at kapitalismo ay magbabago sa anyo ng tersiyaryong edukasyon. May epekto ang pagkalusaw ng mga metapisikal na metanaratibo dahil ang modernong edukasyon ay nakabatay rin sa ilang metapisikal na metanaratibo, katulad ng kaisipang edukasyon bilang humanisasyon ng sangkatauhan at edukasyon bilang liberasyon mula sa kamangmangan, kahirapan, pagdurusa at karamdaman. Sa postmodernong panahon mapipilitan ang edukasyong ibatay ang kanyang sarili sa mga pamantayang ginagamit na ng postmodernong siyensiya: ang episiyensiya para sa metodolohiya at pagiging kapakipakinabang at mabenta ng mga resulta nito. May epekto rin ang komodipikasyon ng kaalaman na resulta ng sabwatan ng siyensiya, estado at kapitalismo dahil mapipilitang tumugon and edukasyon sa mas mataas na pagpapahalaga sa kaalaman sa postmodernong panahon. Ang pagtaya ni Lyotard sa magiging anyo ng tersiyaryong edukasyon ay maaaring ilatag sa ilalim ng apat na puntos: 1) ang inaasahang resulta ng naturang antas ng edukasyon, 2) ang mga tatanggap ng kaalaman, 3) ang magpapadaloy ng kaalaman, at 4) ang kaalamang dapat ipapadaloy. ${ }^{14}$

Naniniwala si Lyotard na tatlo ang pinaka inaasahang resulta ng postmodernong tersiyaryong edukasyon. Una ay ang pagsasanay sa kabataan para sa mga tradisyunal na propesyong kinakailangan para sa pananatili ng takbo ng lipunan, katulad ng medisina, abogasya, pagtuturo at administrasyon. Pangalawa ay ang pagsasanay sa kabataan para sa postmodernong gawaing pagpapalaganap, pag-iimbak at paggamit ng kaalaman. Dahil dito inaasahan ni Lyotard na dadami ang mga mag-aaral na magsasanay sa mga larangan ng siyensiya ng kompyuter, cybernetics,

${ }^{14}$ Ibid., 48.

(C) 2013 F.P.A. Demeterio III

http://www.kritike.org/journal/issue 13/demeterio december2013.pdf ISSN 1908-7330

(cc) BY-NC 
lingguwistika, matematika, lohika at kahalintulad na larangang may kinalaman sa digitalisasyon at pagsasalin ng kaalaman. ${ }^{15}$ Pangatlo ay ang pagsasanay at muling pagsasanay sa mga empleyado para maging mas episiyente sila sa kanilang pagpapalaganap at pangangasiwa ng kaalaman.

Batay sa tatlong inaasahang resultang ito, may apat namang pangkat ng mga indibiduwal na silang tatanggap at makikinabang sa postmodernong tersiyaryong edukasyon. Una ay ang kabataang nagnanais mapabilang sa tradisyunal na mga propesyun. Ayon kay Lyotard kahit pa man magmumula sa hanay ng mga elitista ang kabataang ito, ang kanilang pagsasanay ay hindi na para hubugin silang maging mga bagong elitista kung hindi para hubugin silang maging mga propesyunal na handang magbigay ng kanilang serbisyo para sa tuloy-tuloy na pagtakbo ng lipunan. ${ }^{16}$ Pangalawa ay ang kabataang nagnanais mapabilang sa hanay ng mga postmodernong siyantista at teknolohista. Inaasahan ni Lyotard na mas demokratiko ang demograpiya ng kabataang ito. Sa loob ng pangalawang pangkat ay may nakita siyang posibilidad na magkakaroon ng bahagyang pagkakaiba ang hanay ng mga gagawa mismo ng bagong kaalaman at ang hanay ng mga tagapangasiwa lamang ng kaalaman. ${ }^{17}$ Pangatlo ay ang kabataang hindi malinaw kung ano talaga ang pakay nila sa buhay, at kung sila ay magtapos man sa antas tersiyaryo ay malamang babagsak sila sa hanay ng mga walang trabaho o ng mga manggagawang under-employed. ${ }^{18}$ Pang-apat ay ang mga indibiduwal na nagtatrabaho na ngunit nangangailangan pa ng mga bago at karagdagang kasanayan.

Kumbinsido si Lyotard na sa postmodernong panahon lalakas ang pagkontrola ng estado at kapitalismo sa mga pamantasan, kagaya ng pagkontrola ng mga ito sa siyensiya. Ang pamantayan ng episiyensiya ng metodolohiya at pagiging kapakipakinabang at mabenta ng resulta na dati nang sumaklaw sa siyensiya ay sasaklaw rin sa mga pamantasan. ${ }^{19}$ Dito mawawalan ng otonomiya ang mga pamantasan at susunod na lamang mga dikta ng estado at kapitalismo at sa puwersa ng episiyensiya at pagiging kapakipakinabang at mabenta. Sa ngalan ng episiyensiya at sa ngalan ng pagpapadaloy ng komodipikadong kaalaman, hinihinuha ni Lyotard na dadating ang araw kung kalian ang mga propesor ay papalitan na ng mga kompyuter na mas episyente sa gawaing pagpapadaloy ng nakaimbak na kaalaman. ${ }^{20}$

$$
\begin{aligned}
& { }^{15} \mathrm{Ibid} . \\
& { }^{16} \mathrm{Ibid} . \\
& { }^{17} \mathrm{Ibid} ., 53 . \\
& { }^{18} \mathrm{Ibid} ., 49 . \\
& { }^{19} \mathrm{Ibid} ., 48 . \\
& { }^{20} \mathrm{Ibid} ., 53 .
\end{aligned}
$$


Nakikinita ni Lyotard na may apat na uring kaalaman ang ipapadaloy sa postmodernong pamantasan, depende sa kung sino ang tatanggap sa mga ito. Una, para sa kabataang nagnanais mapabilang sa mga tradisyunal na propesyon, natural lamang na ang tradisyunal na kaalamang angkop sa kani-kanilang espesyalisasyon ang ipapadaloy para sa kanila. ${ }^{21}$ Pangalawa, para sa kabataang nagnanais mapabilang sa hanay ng postmodernong siyantista at teknolohista, sila ang tatanggap ng uri ng edukasyong nakadepende sa mga kompyuter at mga imbakan ng digital na kaalaman. Tuturuan sila kung paano hanapin ang mga angkop na imbakan ng digital na kaalaman at paano hanguin mula sa mga ito ang mga partikular na kaalamang kinakailangan. Tuturuan din sila kung paano maging interdisiplinaryo sa pag-iisip at paano gumawa ng mga bagong koneksiyon mula sa kaalamang nasa dulo na ng kanilang mga kamay.22 Sa loob ng pangkat ng mga kabataang nagnanais mapabilang sa hanay ng mga postmodernong siyantista at teknolohista ay nandoon ang espesyal na grupo ng kabataang magiging tagagawa at tagatuklas ng mga bagong kaalaman, kaya bahagyang naiiba ang kaalamang nararapat ipapadaloy sa kanila, at ito ang pangatlong uri ng kaaalamang ipapadaloy ng postmodernong pamantasan. ${ }^{23}$ Pang-apat, para sa mga empleyadong nagnanais na makamtan ang mga bago at karagdagang kaalaman at kasanayan para sa lalong pagpapahusay sa kani-kanilang trabaho, ang kaalamang ipapadaloy sa kanila ay mga espesipikong unit ng kaalaman na ibibigay sa kanila sa mga espesipikong panahon. ${ }^{24}$

\section{Ang Saysay ng Etika at Katarungan sa Panahon ng mga Munting Naratibo}

Sa pagkalusaw ng mga metanaratibo at dambuhalang kuwento ay nalusaw din ang mga tradisyunal na sistema ng moralidad at etika, at diskurso tungkol sa katarungan. Ngunit dahil kailangan ng anumang lipunan ang mga usaping ito, tungkulin ng mga pilosopong magpanukala ng katanggap-tanggap na sistema at diskurso na pampalit sa mga nalusaw na gabay. Inilahad ni Lyotard ang kanyang panukalang moralidad, etika at padalumat sa postmodernong katarungan sa kanyang mga akdang Just Gaming ng 1979, at The Differend: Phrases in Dispute ng 1983. Mas madaling intindihin ang panukala at dalumat ni Lyotard kapag titingnan ang mga ito bilang reaksiyon sa kahalintulad na pagtangka ng Alemang pilosopo at sosyolohistang si Jurgen Habermas (ipinanganak: 1929) na magtayo ng

\footnotetext{
${ }^{21}$ Ibid., 50.

${ }^{22}$ Ibid., 52.

${ }^{23} \mathrm{Ibid} ., 53$.

${ }^{24}$ Ibid., 49.
} 
modernong sistema ng etika at teorya ng katarungan sa panahong lumilipas na ang mga tradisyunal na diskursong nakabatay sa unibersalismo at naturalismo.

Sa panahong itinakwil na ng mga pilosopo at modernong indibiduwal ang paniniwala na mayroong unibersal at natural na mga batas na dapat gawing batayan ng anumang sistema ng moralidad, etika at teorya ng katarungan, naniniwala pa rin si Habermas sa posibilidad ng pagkakaroon ng modernong sistema ng moralidad, etika at teorya ng katarungan. Dahil ang mga ito ay balak niyang ibatay sa anumang kasunduan (consensus) ang mararating sa lahat ng may kinalaman sa mga partikular na usapin matapos ang masinsinang talakayan at diskusyon. Kaya tinatawag ni Habermas ang kanyang panukalang sistema bilang "discourse ethics." Para mapanatili ang integridad ng proseso ng talakayan at diskusyon at ng pagkamit ng kasunduan inilatag niya ang kanyang mga ideya ng komunikatibong aksiyon at ideal speech situation.

Para kay Habermas, ang komunikatibong aksiyon ay ang kabaliktaran ng estratihikong aksiyon kung saan ang pakikipag-ugnayan at pakikipag-usap sa iba ay nagmumula sa pagnanais na talunin, manipulahin at kontrolin ang iba. Kapag ang estratihikong aksiyon ang papairalin, walang mangyayaring masinsinang talakayan at diskusyon dahil ang buong usapan ay maaaring manipulahin at kontrolin ng sinumang pinakamatalino, pinakamaalam, pinakamahusay magsalita, at pinakamakapangyarihan. Kaya anumang kasunduan ang mararating sa loob ng talakayan at diskusyong ito ay kikiling sa panig ng mga pinakamatalino, pinakamaalam, pinakamahusay, at pinakamakapangyarihan, at hindi maaaring ituring na isang etikal at makatarungang pamantayan. Sa kabilang dako, ang komunikatibong aksiyon ay isang uri ng pakikipag-ugnayan at pakikipag-usap sa iba na nagmumula sa pagnanais na makamtan ang isang kasunduan kahit hahantong pa ito sa puntong isasantabi na ng sarili ang kanyang mga naunang opinyon at kagustuhan. Para lalong mapanatili ang pagkadalisay ng proseso ng talakayan at diskusyon iminungkahi ni Habermas na ang komunikatibong aksiyon ay dapat gaganapin sa loob ng isang ideal speech situation. Sa kanyang libro na Moral Consciousness and Communicative Action, inihayag niya ang kanyang limang panuntunan para maitatag ang isang ideal speech situation: 1) lahat ng indibiduwal na may kakayahang magsalita at umaksiyon ay maaaring sumali sa diskurso; 2) lahat ng kasali sa diskurso ay maaaring pumuna, o magtanong, sa anumang nailabas nang pahayag; 3 ) lahat ng kasali sa diskurso ay maaaring maglabas ng pahayag; 4) lahat ng kasali sa diskurso ay maaaring maglabas ng kanilang mga panananaw, pagnanais at pangangailangan; at 5) walang tagapagsalita ang maaaring 
pigilan, sa pamamagitan ng internal o eksternal na puwersa, na gampanan ang mga nauna nang panuntunan (Tingnan sa Habermas 86). ${ }^{25}$

Kahit malaki ang potensiyal ng discourse ethics ni Habermas na makagawa ng isang mapagkatiwalaan at maaasahang modernong sistema ng moralidad at etika at teorya ng katarungan maaaninag na natin ang mga pilosopikal na problema at bagaheng dala nito. Katulad halimbawa sa katanungang kaya ba talaga ng isang modernong indibiduwal na isantabi ang kanyang mga opinyon at kagustuhan alang-alang sa pagkakaroon ng kasunduan, o sa katanungang kaya ba talaga ng lahat na may kinalaman sa partikular na usapin na aktibong makibahagi sa masinsinang talakayan at diskusyon. Sa librong Just Gaming ang pagtutol ni Lyotard sa posibilidad ng pagkakaroon ng modernong sistema ng moralidad, etika at teorya ng katarungan na batay sa diskursibong kasunduan ay inihayag niya gamit ang konsepto ng language game ng Austriyanong pilosopong si Ludwig Wittgenstein (1889-1951). Ang language game ni Wittgenstein ay tungkol sa prinsipyong walang unibersal na panuntunan ang wika at wala ring unibersal na kahulugan ang mga salita. Binigyang diin ni Wittgenstein na ang mga panuntunan at kahulugan ay nakabatay sa mga tiyak na konteksto, o laro, kung saan ang wika, o salita, ay ginagamit. Nagbabala si Wittgenstein na may inklinasyon ang tao na gamitin ang panuntunan at pangahulugan ng isang isang language game para sukatin ang ibang language game. Kagaya ng hindi natin nilalaro ang basketball gamit ang mga panuntunan ng baseball, hindi din natin susukatin dapat ang relihiyon, halimbawa, gamit ang mga panuntunan at pangahulugan ng siyensiya o panulaan. Para kay Lyotard ang diskursibong kasunduan ni Habermas ay posible lamang sa mga limitadong pagkakataon kung kailan nagmumula sa iisang language game ang lahat ng may kinalaman sa partikular na usapin. Dahil sa mas maraming pagkakataon nagmumula sa iba't ibang language game ang lahat ng may kinalaman sa partikular na usapin, mas madalas imposibleng makamtan ang tunay na diskursibong kasunduan. Sa mas maraming pagkakataon nagiging dominante ang isang makapangyarihang language game at pilit ipapataw nito ang kanyang mga panuntunan at pangahulugan sa ibang language game. Sa mga ganitong sitwasyon pinipipi ng dominanteng language game ang ibang language game.

Sa librong Just Gaming, tila simple lamang ang naging depinisyon ni Lyotard sa "kawalan ng katarungan" at sa "katarungan." Para sa kanya, ang kawalan ng katarungan ay nagaganap kapag "ang posibilidad para maglaro sa laro ng makatarungan (game of the just) ay naglaho na;" habang ang katurangan naman ay nagaganap kapag binibigyan natin ang iba ng

${ }^{25}$ Jürgen Habermas, Moral Consciousness and Communicative Action (Cambridge: MIT Press, 1990), 86.

(C) 2013 F.P.A. Demeterio III

http://www.kritike.org/journal/issue 13/demeterio december2013.pdf

ISSN 1908-7330

(cc) BY-NC 
panahong makibahagi sa laro ng makatarungan, respeto sa kanilang pagkakaiba, at pagkataong magsalita para sa kanilang sarili. ${ }^{26}$ Ibig sabihin, para kay Lyotard hindi mahalaga ang diskursibong kasunduan, kapag ito ay nakamtan sa pamamagitan ng malay o hindi malay na pagpipi sa ilang mga kabahagi ng partikular na talakayan at diskusyon. Sa halip mas mahalaga para sa kanya ang pagiging bukas loob para sa katotohanang sa mas maraming pagkakataon may mga pagkakaiba ang mga kabahagi ng partikular na talakayan at diskusyon na hindi talaga maaaring isantabi at ibaon sa ilalim ng isang kuwestiyonableng kasunduan.

Sa librong The Differend: Phrases in Dispute, ginamit ni Lyotard ang salitang "differend" bilang katawagan niya para sa sitwasyong hindi talaga maaaring pagtagpuin ang dalawa o higit pang mga language game dahil sa kanilang malalalim at malalawak na pagkakaiba-iba. Isinulat ni Lyotard: "Hindi katulad sa litigasyon, ang differend ay isang kaso ng tunggalian, sa pagitan ng dalawang partido (o higit pa), na hindi mareresolba dahil sa kawalan ng panuntunan sa paghusga ng magkabilaang argumento." ${ }^{27}$ Ang etika at teorya ng katarungan ni Lyotard ay isang panawagan para sa mga malaki at makapangyarihang language game na sana ay sisikapin nilang pakinggan at intindihin ang maliit at walang kapangyarihang language game para hindi nila masasagaan ang mga ito sa kanilang pagmamadaling bumuo ng dispalinghadong kasunduan.

\section{Ang Saysay ng Sining sa Postmodernong Panahon}

Ang usapin tungkol sa sining at astetika ay mahalaga para kay Lyotard hindi lamang para mabigyang saysay ang modo na avant-garde, na noon ay kaliwa at kanang binatikos ng mga konserbatibo, kung hindi pati na sa puntong ang sining at astetika ng modong avant-garde ay may malalim na kinalaman at implikasyon sa kanyang pulitikal, etikal at moral na hangaring mabigyan ng espasyo at atensiyon ang differend at ang maliliit na naratibo. Inilatag ni Lyotard ang kanyang astetika sa marami niyang libro at sanaysay, katulad ng Duchamp's Transformers ng 1977, The Inhuman: Reflections on Time ng 1988, at Lessons on the Analytic of the Sublime: Kant's Critique of Judgment ng 1991. Ngunit may isang maikling sanaysay na inilathala niya noong 1982 na malinaw na nagpapahayag sa kanyang teorya ng sining, ang "Answering the Question: What is Postmodernism?" Ang

26 Jean-Francois Lyotard, Just Gaming (Minneapolis, Minnesota: University of Minnesota Press, 1985), 67; tingnan din sa Simon Malpas, Jean-François Lyotard (New York: Routledge, 2003), 57.

${ }^{27}$ Jean-Francois Lyotard, The Differend: Phrases in Dispute (Manchester: Manchester University Press, 1988), xi.

(c) 2013 F.P.A. Demeterio III http://www.kritike.org/journal/issue 13/demeterio december2013.pdf ISSN 1908-7330 
sanaysay na ito ay nakalakip bilang apendiks sa 1984 na salin ng The Postmodern Condition: a Report on Knowledge.

Mas madaling intindihin ang teorya ng sining ni Lyotard kapag ito ay titingnan bilang pagsang-ayon, reaksiyon at modipikasyon sa mga astetikal na diskurso ng dalawang pantas ng Frankfurt School: ang Alemang musikolohista, kompositor, pilosopo, kritiko ng kultura, at sosyolohistang si Theodor Adorno (1903-1969), at ang nabanggit na nating si Habermas. Naniniwala si Adorno na ang mas seryosong sining ay hindi dapat magmumukhang natural, normal at pamilyar para sa mga tagapagtangkilik nito. Sa halip, ang mas seryosong sining para sa kanya ay iyong nangangailangan ng sapat na panahon at enerhiya para lubusang maintindihan at magustuhan. Kaya para matupad ang batayang ito dapat sisikapin ng manlilikhang sining na tanggihan ang komersyalisasyon at ang kasama nitong mga proseso ng istandardisasyon at huwad na indibiduwalisasyon. Kinatigan ni Adorno ang modong avant-garde bilang mas seryosong sining, dahil para sa kanya ito ay nakabatay sa mga prinsipyong dapat tuloy-tuloy nitong labagin ang anumang naghaharing tradisyon at sistemang pansining, at dapat makatotohanan nitong ihayag ang pagdurusa ng modernong tao. Isinulat ng kanyang komentaristang si Martin Jay: “Tanging sila (mga manlilikha ng sining na avant-garde) lamang ang may taglay ng masaklap na patotoo sa pagkalusaw ng subject ng modernong buhay...Tanging sila lamang ang umagaw mula sa obhektibong pagguho ng wika ng isang negatibong imahen ng mundo na maaaring pagmumulan ng kahulugan balang araw." 28

Dating guro ni Habermas si Adorno ngunit lumihis siya sa direksiyon ng astetika ng nakatatandang pilosopo at nagnanais dalhin ang sining, na sa kanyang pananaw ay lumipad na palayo nang palayo, pabalik sa lipunan at buhay ng mga tao. Napansin ni Habermas na isa sa mga dikaaya-ayang epekto ng modernismo ay ang pagkakaroon ng lipunan ng sobra-sobrang espesyalisasyon sa puntong hindi na nagkakaintindihan ang mga indibiduwal na nagmumula sa magkakaibang espesyalisasyon. Halimbawa, sa pananaw ng pangkaraniwang tao ang modo na avant-garde ay hindi na maiintindihan dahil nakatuon na lamang ang sining na ito sa ibang manlilikha ng kaparehong sining at sa ilang teoresista ng astetika. Sa halip na hayaan na lamang na sumabog pa ang kultura at lipunan sa marami ngunit makikitid na espesyalisasyon, iminungkahi ni Habermas na dapat ang sining ang magtatahi at maghihilom sa mga sugat at pagkakawatak-watak ng modernismo. ${ }^{29}$ Kagaya ng kanyang teorya ng katarungan na nakabatay sa pagkakaroon ng diskursibong kasunduan,

130.

${ }^{28}$ Martin Jay, Adorno (Cambridge, Massachusetts: Harvard University Press, 1984),

${ }^{29}$ Lyotard, The Postmodern Condition, 72.

(C) 2013 F.P.A. Demeterio III

http://www.kritike.org/journal/issue 13/demeterio december2013.pdf

ISSN 1908-7330

(cc) BY-NC 
gustong gawin ni Habermas ang sining bilang istrumento sa pagkakaroon ng pagkakaintindihan sa pagitan ng mga modernong espesyalisasyon.

Parehong may pulitikal, etikal at moral na dimensiyon ang mga teorya ng sining nina Adorno at Habermas, ngunit mas kinatigan ni Lyotard ang dalumat ni Adorno kaysa dalumat ni Habermas. Hindi na dapat natin ito ikagugulat dahil alam na natin ang kawalan ng tiwala ni Lyotard sa proseso ng diskursibong kasunduan at pagkakaintindihan na nauna nang inihayag ni Habermas sa kanyang teorya ng katarungan. Gayunpaman, hindi rin basta na lamang tinanggap ni Lyotard ang malaeksistensiyalistang pananaw ni Adorno tungkol sa avant-garde. Sa halip, tinakalakay niya ang saysay ng avant-garde kaugnay sa kanyang mas malawak na gawaing pakikipaglaban para sa differend at maliliit na naratibo. Ginawa niya ito sa tulong ng astetikal na diskurso an Alemang pilosopo na si Immanuel Kant (1724-1804). Ayon kay Kant may dalawang bagay na pinagtutuunang pansin ang astetika: ang kagandahan at ang sublime. Ang sublime ay may dalawang uri, matematikal at dinamiko. Ang matematikal na sublime ay maaaring magaganap sa isang tao habang minamasdan niya ang isang dambuhalang bagay, katulad ng malaking bundok o gusali, na hindi na niya kayang isipin ang hangganan at porma nito; habang ang dinamiko na sublime ay maaaring magaganap naman sa isang tao habang minamasdan niya ang isang nakamamanghang puwersa, katulad ng bagyo, na alam niyang kaya siya nitong lamunin at sirain sa anumang segundo. Para kay Kant, ang astetika ng sublime ay tungkol sa pinaghalong pakiramdam ng takot at kaligayan.

Dahil alam ni Lyotard na mahirap hanapin ang kagandahan sa mga likhang sining ng modong avant-garde, ginamit niya ang pangalawang bagay ni Kant nang ipinaliwanag niya na ang astetika ng modong avantgarde ay hindi tungkol sa kagandahan kung hindi sa sublime. ${ }^{30}$ Ngunit nang inangkin ng Lyotard ang konsepto ng sublime mula kay Kant, hinubog niya ito sa konteksto ng kanyang post-istraktural na epistemolohiya. Sinabi niya: "Ang sublime ay isang kakaibang sentimiyento. Ito ay nagaganap. . . kapag pumalya ang imahinasyon sa pagrepresenta ng isang bagay."31 Para kay Lyotard ang moderno at postmodernong astetika ay parehong may kinalaman sa sublime. Binigyan niya ng depinisyon ang modernong astetika bilang tungkol sa "pagpapakita na may mga bagay na kahit pa man maaaring isipin ay hindi talaga makikita at maipapakita." ${ }^{32}$ Sa modernong astetika, ang pagkukulang na ito ay naka-ugat sa pagkukulang ng alagad ng sining bilang tao, kaya kadalasan may kulay itong kalungkutan at panghihinayang. Sa kabilang banda, ang postmodernong astetika ay

\footnotetext{
${ }^{30}$ Ibid., 77.

${ }^{31}$ Ibid., 78.

32 Ibid.
}

(c) 2013 F.P.A. Demeterio III http://www.kritike.org/journal/issue 13/demeterio december2013.pdf ISSN 1908-7330 
parehong tungkol sa pagpapakita sa mga bagay na hindi makikita at maipakita ngunit nakaugat na sa kagalakan at pagkamapaglaro ng alagad ng sining. Ito ay dahil para kay Lyotard ang teorya ng sining ay tungkol sa patuloy na pagtangka ng mga alagad ng sining na sa pamamagitan ng sublime ay maimungkahi nila sa lipunan na bigyang espasyo ang differend at maliliit na naritibo. Dramatikong niyang isinulat sa pinakadulo ng kanyang sanaysay: "makipagdigma tayo sa totalidad; maging saksi tayo sa hindi mairepresenta; pairalin natin ang pagkaka-iba-iba para mailigtas natin ang dangal ng pangalan." 33

\section{Mga Mahalagang Puntos mula sa Kaisipan ni Lyotard para sa ating Lokal na Pag-aaral ng Teksto at Kultura}

Binanggit sa introduksiyon na isa sa mga hangarin ng papel na ito ay ang pagtukoy sa mga aspekto at punto mula sa kaisipan ni Lyotard na may maiaambag para sa lalong pagpapayaman sa teoretikal na korpus ng lokal nating araling cultural at araling Pilipino. Kaya sa seksiyong ito hahalawin natin mula sa pilosopiya ni Lyotard ang ilang aspekto at punto na magagamit natin sa pagpapayabong sa ating sariling tekstuwal at kultural na mga pagsusuri.

Una, sa konteksto ng lipunang Pilipino, malaki ang saysay at potensiyal na gamit ng diskurso ni Lyotard tungkol sa tunggalian ng mga dambuhalang naratibo at mga maliit na naratibo. Mapapakinabangan nang lubusan ang diskursong ito sa ating pagbalangkas sa ating kolonyal at neokolonyal na kalagayan bilang tunggalian ng mga makapangyarihang dayuhang naratibo at kapus sa kapangyarihang lokal na mga naratibo; pati sa ating pagdalumat sa ating multikultural na kondisyon bilang interaksiyon ng mga pang-etnikong naratibo; pati na rin sa ating pagtalakay sa pulitika ng mga kasarian bilang pakikipag-ugnayan ng iba't ibang pangkasariang naratibo; at lalo na sa ating pagresolba sa madalas maiinit na bangayan sa pagitan ng mga pananampalataya, at ng mga pananampalataya at ng sekular nating estado. Ang pilosopiya ni Lyotard tungkol sa mga dambuhalang naratibo at mga maliit na naratibo ay hindi lamang magbibigay sa atin ng teoretikal na lente para masuri ang iba't ibang tunggalian na bumabagabag sa ating lipunan, kung hindi pati na sa isang mahalagang pangangaral na sa isang moderno o postmodernong lipunan dapat ay paiiralin ang respeto para sa pagkaka-iba-iba.

Pangalawa, ang pagsuri ni Lyotard sa katayuan at istraktura ng siyensiya sa moderno at postmodernong mga bansa ay maaaring gawin nating batayan sa pagsuri sa katayuan at istraktura ng siyensiya sa

${ }^{33}$ Ibid., 82.

(C) 2013 F.P.A. Demeterio III

http://www.kritike.org/journal/issue 13/demeterio december2013.pdf ISSN 1908-7330

(cc) BY-NC 
Pilipinas. Sa usaping ito maaari nating ilahad ang mga sumusunod na katanungan: moderno na nga ba ang ating siyensiya?; ano ang mga metanaratibong ginagamit ng ating mga pinuno at intelektuwal para kumbinsihin ang ating mga kapwa Pilipino sa halaga ng siyensiya?; makabuluhan nga bang dalhin ang ating siyensiya sa moderno o hindi kaya postmodernong antas?; ano ang kumpigurasyon ng sabwatan ng siyensiya, estado at kapitalismo sa ating saliring konteksto?; at mga kahalintulad pang katanungan.

Pangatlo, ang parehong pagsusuri ni Lyotard sa katayuan at istraktura ng siyensiya ay maaaring magbibigay sa atin ng reyalisasyon na ang ating napabayaang siyensiya at teknolohiya ay magdudulot ng kahinaan sa ating hangaring sugpuin ang kolonyalismo at neokolonyalismo dahil ang labanan ngayon ay nasa larangan na ng paggawa at pag-imbak ng mga kaalaman kung saan madedehado lalo ang mga bansang mahirap na walang sapat na kapital para sumali man lamang sa naturang labanan. Sa labanang ito, lamang na lamang ang mga bansa at higanteng korporasyon na nauna na sa paggawa at pag-imbak ng kaalaman at may malalaking pondong pantustus sa mga kasangkapan ng pananaliksik. Ngunit may kabalintunaang dala ang reyalisasyong ito, sa puntong kapag nagsusumikap naman tayong palakasin ang ating siyensiya ay baka naman malagay sa panganib ang ating mga tradisyunal na gawain at aspekto ng ating multi-etnikong kultura. Gayunpaman may potensiyal ang pagsusuri ni Lyotard na magamit natin bilang gabay sa paghahanap sa maselang balanse sa pagitan ng ating hinahangad na siyantipikong kaunlaran at ng ating tungkuling protektahan ang otonomiya ng ating mga tradisyunal at multi-etnikong naratibo.

Pang-apat, ang pagtaya ni Lyotard sa magiging anyo ng postmodernong tersiyaryong edukasyon ay maaaring magbigay sa atin ng konseptuwal balangkas para punahin ang ating sistema ng tersiyaryong edukasyon na kumikiling pa rin sa mga tradisyunal na propesyon kaysa mga moderno man lamang na gawaing pagtutuklas at pagpapalaganap ng mga bagong kaalaman. Kapag titingnan natin ang ating mga pamantasan at kolehiyo makikita natin kaagad na mas marami sa ating kabataan ay nasa mga programang may mas mataas na pangako para sa agarang pagkakaroon ng trabaho sa halip na nasa mga programang nakababad sa siyensiya, mas mataas na teknolohiya at pananaliksik. Ang diskusyon ni Lyotard tungkol sa postmodernong tersiyaryong edukasyon ay dapat magbibigay sa atin ng reyalisasyon na kapag gusto nating labanan ang neokolonyalismo at imperyalismo ng mga makapangyarihang estado ay dapat maglaan tayo ng sapat na kapital at oportunidad para sa pagpapalakas ng ating edukasyon sa siyensiya at teknolohiya. 
Panglima, ang parehong pagtaya ni Lyotard sa magiging anyo ng postmodernong tersiyaryong edukasyon, kung saan binigyan niya ng diin ang mga katangian at estratehiyang pagiging pamantasang nananaliksik (research university), pagtuon sa hinahangad na produkto (outcomes based), pagiging interdisiplinaryo, at pagkakaroon ng probisyon para sa patuloy na edukasyon (continuing education), ay maaari ring magbigay sa atin ng konseptuwal na balangkas para sa lalong pagpapalakas ng ating tersiyaryong edukasyon at ng intelektuwal at kultural na kapital ng ating mga manggagawa at propesyunal. Sa usaping ito maaari nating ilahad ang mga sumusunod na katanungan: sapat ba ang bilang ng ating mga pamantasang nakatuon sa pananaliksik kung ihahambing sa mga nakatuon lamang sa pedagohiya (teaching university)?; sapat ba ang mga pananaliksik na naganap sa ating mga pamantasang nananaliksik?; ano nga ba ang ating mga hinahangad na katangian na dapat makamtan ng ating mga graduwado?; malinaw ba ang mga ito?; posible ba ang mga itong makamtan?; paano nga ba ang mga ito nabuto at naisulat ng ating mga pamantasan?; naintindihan na ba ng ating mga guro ang benepisyong maaaring idulot ng interdisiplinaryong edukasyon at pananaliksik?; may mga departamento na ba ang ating mga pamantasan para sa patuloy na edukasyon ng ating mga mangagawa at propesyunal?; at mga kahalintulad na katanungan.

Pang-anim, ang teoryang etikal at pangkatarungan ni Lyotard na bumatikos sa diskursibong etika at teorya ng katarungan ni Habermas at sa halip ay nagbigay diin sa mga aspektong madalas ay nasasagasaan ng nagmamadaling proseso ng pagkakasundo ay may malaking maiiambag sa pagpapairal ng etikal na pamantayan at sistema ng katarungan sa isang bansa, katulad ng Pilipinas, kung saan malawak ang agwat sa pagitan ng mayayaman at mahihirap, makakapangyarihan at mga kapus sa kapangyarihan, at mga may edukasyon at mga kulang sa edukasyon. Ang pinakamahalagang aral na maibabahagi ni Lyotard sa mayayaman, makakapangyarihan at mga may edukasyon ay sana maging mas sensitibo sila sa katotohanang madalas ang kanilang nakakasalamuhang kapwa Pilipino ay walang kakayahang makipagtalakayan sa kanila, o kulang sa kakayahang maglahad sa lahat ng kanilang mga saloobin, o kaya nagmumula sa kakaibang naratibo. Para kay Lyotard ang pagkakaroon ng kasunduan ay hindi makakamtan sa isang mekanikal na proseso ng paguusap kung hindi sa isang mala-penomenolohikal na proseso kung saan kinakailangan ang mahabang pasiyensiya sa pag-intindi sa radikal na pagkaka-iba-iba ng mga kabahagi ng proseso ng pagkakasundo.

Pampito, ang astetika ng sublime at differend na iminungkahi ni Lyotard ay mapapakinabangan nang husto sa ating konteksto kung saan may marami nang Pilipinong manlilikha ng sining na sumusubok sa, at 
nagpapalaganap ng, modong avant-garde, ngunit dahil sa ating kakulangan sa moderno at postmodernong astetikal na kaalaman ay madalas hindi natin sila naiintindihan. Bilang kongkretong halimbawa, alalahanin natin ang gusot na nilikha ng instalasyong "Politiesmo" ni Mideo Cruz na itinanghal sa Cultural Center of the Philippines mula Hunyo hangang Agosto ng taong 2011. Ang astetika ni Lyotard ay isa lamang sa mga astetikang maaaring magbibigay ng kabuluhan sa isang modo ng sining na may ilang representasyon na rin sa ating bansa. Panahon nang mulatin ang ating kapwa Pilipino na ang sining ay hindi lamang tungkol sa kagandahan kung hindi pati na sa sublime. Ang astetika ni Lyotard ay maaari ring magpapalakas sa kontemporaryong sining sa ating bansa dahil sa kanyang pagbigay diin sa ugnayan sa pagitan ng sining, pulitika at etika, sa puntong ang paglikha ng sining ay isang pakikibaka para sa differend.

Department of Filipino, De La Salle University-Manila, Philippines

\section{References}

Habermas, Jürgen, Moral Consciousness and Communicative Action (Cambridge: MIT Press, 1990).

Jay, Martin, Adorno (Cambridge, Massachusetts: Harvard University Press, 1984).

Lyotard, Jean-Francois, Just Gaming (Minneapolis, Minnesota: University of Minnesota Press, 1985).

The Differend: Phrases in Dispute (Manchester: Manchester University Press, 1988).

The Postmodern Condition: a Report on Knowledge (Minneapolis, Minnesota: University of Minnesota Press, 1984).

Malpas, Simon, Jean-François Lyotard (New York: Routledge, 2003). 